\title{
Calco de Richard Hamilton: estrategias de reelaboración de obras de arte internacionales en contextos locales
}

\author{
Luis Alejandro Mosquera Delgado
}

L a Vitrina de la Fundación Lugar a Dudas ${ }^{1}$ está ubicada en el Barrio Granada, en el centro de la ciudad de Cali, Colombia, un lugar tradicional que - en la última década ha cambiado de una zona residencial a un destino turístico, comercial y gastronómico. Se inauguró en diciembre de 2006 con la proyección en video de la performance La Vitrina, de María Teresa Hincapié. Entre las exhibiciones que han hecho parte de este espacio están: La botella de coca cola llena de coca cola, de Luis Camnitzer (2007); la instalación Felipe Herradura, de Leonardo Herrera (2008); Cartillas para aprender historia, de Gabriela Pinilla (2009); la acción En vitrina, de Paola Gaviria (2010) y la video instalación It's hard to make a living as an artist (Es difícil ganarse la vida como artista), de Luis Hernández Mellizo (2011), entre otros.

Como parte de este espacio de exhibición, el programa "Calco" propone la reelaboración de obras de arte contemporáneo pertenecientes a diferentes colecciones del mundo, en un intento de acercarlas al público de la ciudad. De acuerdo con el Diccionario de la Real Academia Española, calco es "la acción y efecto de calcar (imitar, copiar o reproducir)" (DRAE 2012). En el caso de La Vitrina, este concepto es desplazado de la educación en artes visuales ${ }^{2}$ al ámbito museográfico, en una reflexión que aborda las condiciones de las academias que, alejadas de los principales centros de exhibición internacional, recurren a la enseñanza de la historia del arte a partir de imágenes reproducidas, impresas sobre una superficie o proyectadas en una pantalla: reproducciones que permiten, además de acceder al índice ${ }^{3}$ de la obra de arte, elaborar copias corporales efímeras ${ }^{4}$ a partir de ellas.

\footnotetext{
${ }^{1}$ La organización Lugar a Dudas es un espacio independiente sin ánimo de lucro que fundó el artista Óscar Muñoz y Sally Mizrachi, en el cual se promueve y difunde la creación artística contemporánea, facilitando el desarrollo de procesos creativos y provocando la interacción de la comunidad a través de las prácticas artísticas (Lugar a Dudas 2011).

${ }^{2}$ Es importante mencionar el caso del artista colombiano Roberto Pizano, quien en 1928 viajó a Europa e importó 1653 grabados y 242 esculturas (reproducciones) destinadas a la enseñanza de las artes en Bogotá.

${ }^{3}$ 1. m. Indicio o señal de algo. [DRAE 2012].

${ }^{4}$ Para este caso utilizo el término de "copias corporales efímeras" para referirme a las copias que no son resultado de un proceso químico o digital de reproducción de imágenes (fotografía, fotoco-
} 
Dentro de este programa, del 26 de noviembre al 17 de diciembre de 2011, se realizó la exposición Calco de Richard Hamilton. Para ésta se llevó a cabo una copia reelaborada de la obra Just what is it that makes today's homes so different, so appealing? (¿Pero qué es lo que hace a los hogares de hoy tan diferentes, tan atrayentes?), desarrollada por estudiantes del Instituto Departamental de Bellas Artes de Cali, asesorados por la docente María Eugenia Duque. El proyecto se basó en una reproducción bidimensional de la obra, a partir de la cual se produjo una interpretación que, aunque guarda relación con el original, no es su copia fiel, pues se trata de una suerte de traducción de sus dimensiones y composición, ambas alteradas considerablemente para adaptarlas a las particularidades del espacio de $\mathrm{La} \mathrm{Vi-}$ trina (Figura 1).

Abierta a una concurrida calle de la ciudad de Cali, La Vitrina, como su nombre lo indica, es un escaparate adyacente al espacio público: a diferencia de uno comercial, en la segunda se realizan exposiciones temporales de obras de arte contemporáneo. Su interior es un cubo blanco irregular de $287 \times 300 \times 216$ $\mathrm{cm}$ de alto: un espacio cerrado que permite que el espectador ${ }^{5}$ mire sólo a través de un cristal de $175 \times 228$ $\mathrm{cm}$. En su interior, La Vitrina guarda todas las características de un cubo blanco; un modelo de galería contemporánea diseñada para intervenciones temporales:

Sin sombra, blanco, limpio, artificial: el espacio está dedicado a la tecnología de la estética. [...] El espacio propone la idea de que mientras los ojos y las mentes están invitadas, los cuerpos que ocupan el espacio no lo están, o sólo son to-

pia etc.) y que están hechas de antemano para permanecer por periodos limitados de tiempo. ${ }^{5}$ Para Barthes el espectador es aquel que compulsa "en los periódicos, libros, álbumes o archivos, colecciones de fotos" (Barthes 1989: 30).

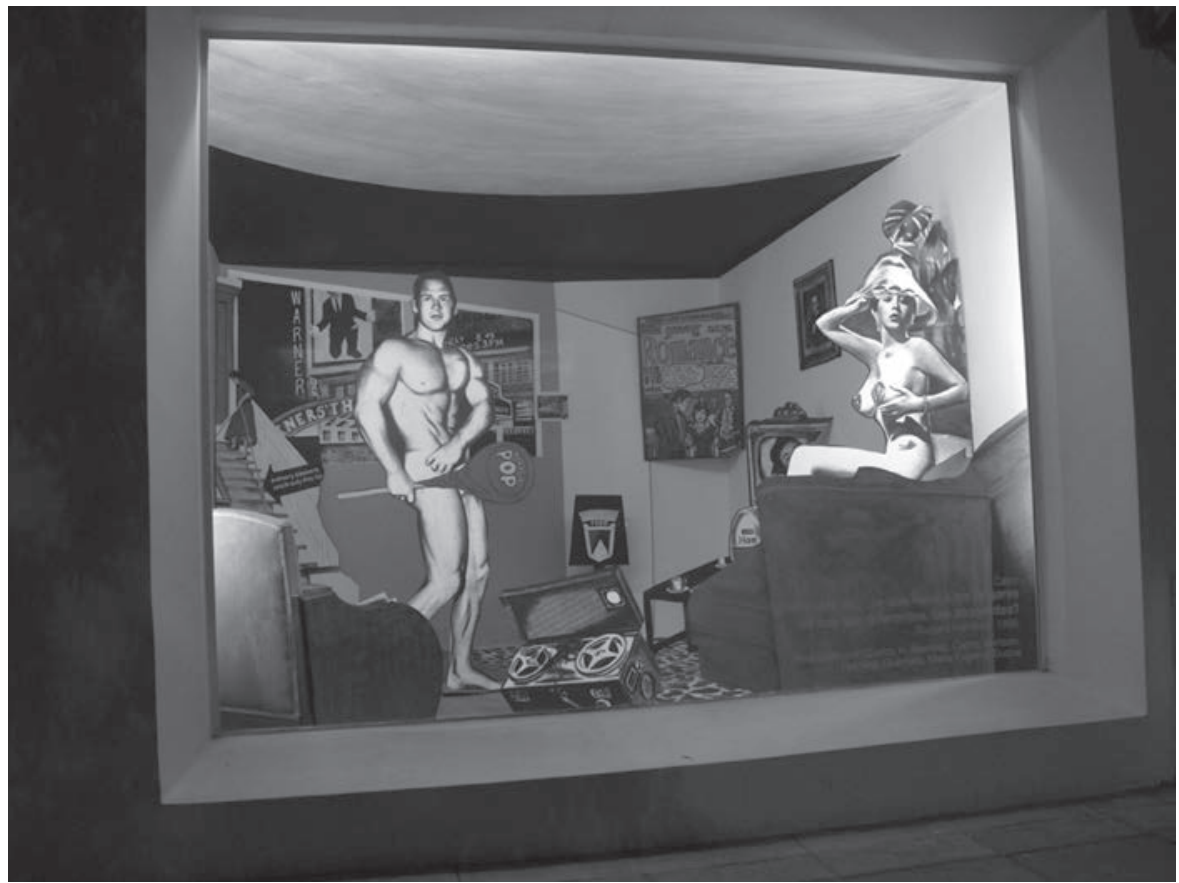

FIGURA 1. Vista exterior de Calco de Richard Hamilton en La Vitrina (Fotografía Fundación Lugar a Dudas, 2011; cortesía: Fundación Lugar a Dudas).

lerados como maniquís cinestésicos para su posterior estudio. [...] Aquí finalmente el espectador, en sí mismo, es eliminado. Estás ahí sin estar ahí: uno de los mayores servicios provistos por el arte y su viejo antagonista, la fotografía. (O'Doherty 1986: 15 , traducción del autor)

Tras del cristal nos encontramos, como lo plantea O'Doherty (1986), con un campo liberado de toda interrupción que permite la existencia (exhibición/ presencia) de la obra de arte y evidencia los procesos implicados en la reelaboración, recontextualización y disposición del espacio de la galería contemporánea. Un cambio considerable en la elaboración de este calco es la sustitución de soporte y formato. El calco, al haber sido elaborado a partir de una imagen obtenida de internet, ya no es un collage como el original: sus figuras son ampliaciones recortadas e intervenidas por medio de diferentes técnicas pictóricas que buscan acercarse al color de la imagen de referencia. Los recortes se distribuyen en el espacio de La Vitrina para aproximarse a la composición del original, en una puesta en escena verosímil que ilustra la obra de arte (Figura 2); ${ }^{6}$ una ilustración para la cual se indaga sobre los procesos de elaboración de la imagen, con el fin de obtener otros procedimientos accesibles que se acerquen a la apariencia de ésta, enfocándose en la obra per se mas no en la intención del autor respecto de ella.

En términos de recepción, el cristal es un marco que establece una relación virtual entre el espectador y la copia de la obra, pues delimita la perspectiva del espacio, de manera semejante a las fotografías impresas que posibilitan el acceso fragmentario a la representación de un objeto. Pero, a diferencia de la reproducción fotográfica, aquí se propone la construcción de una obra para un evento efímero, en tanto la duración expositiva del Calco es breve: finalizado el evento la copia se desmantela, y así concluye su estatus provisional de reproducción. Este programa de exhibición busca que la

\footnotetext{
${ }^{6}$ Para facilitar la comparación entre el Calco de Richard Hamilton y el collage, véase Rummel 2006.
} 


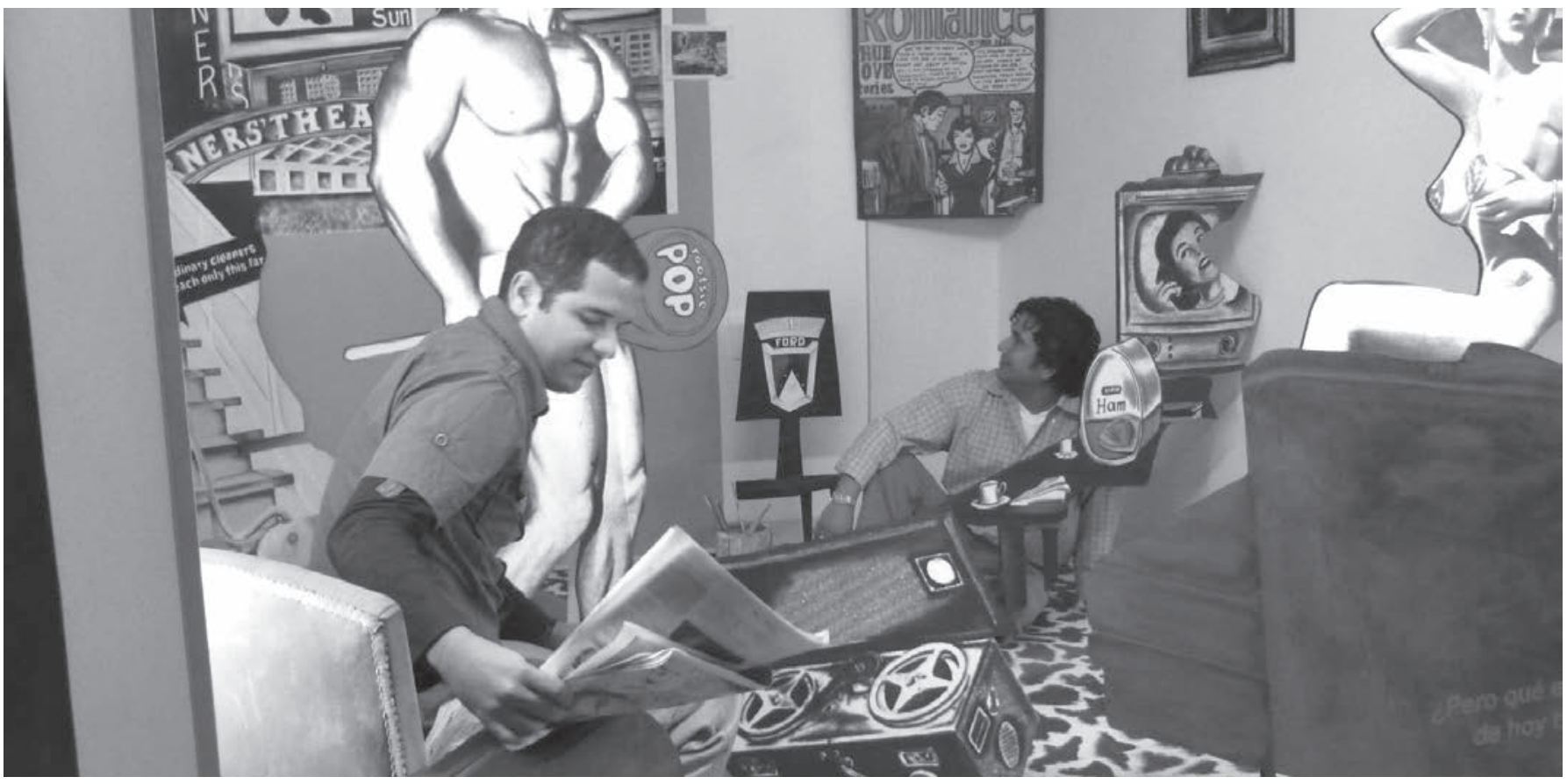

FIGURA 2. Detalle del interior del Calco de Richard Hamilton en La Vitrina (Fotografía Fundación Lugar a Dudas, 2011; cortesía: Fundación Lugar a Dudas).

obra de arte sobreviva en el imaginario del espectador, como lo plantea André Malraux (1951) en Le musée imaginaire. Laura González (2011: 2), en referencia a la obra de este autor, nos invita a pensar cómo "la fotografía aportaba una profusión de obras de arte" a los artistas y cómo éstas dejan de estar ligadas a su lugar de origen. ${ }^{7}$ Así como el impreso o la imagen fotográfica permiten acceder a la imagen de la obra sin tener que trasladarnos al lugar donde se encuentra, la reproducción corpórea nos da entrada a una reflexión sobre la evidente distancia que existe entre la obra original y el público.

Este espacio museográfico intenta atrapar la atención del transeúnte; a modo de un escaparate comercial, nos ofrece un objeto que no es po-

\footnotetext{
${ }^{7}$ El espacio al que se refiere es el de la página impresa, que por medio de la fotografía, permite relacionar diferentes obras de arte con base en un mismo criterio.
}

sible adquirir corpóreamente pero sí asimilarlo en la memoria. Una reproducción que busca reactivar el imaginario de una obra de arte no sólo presentándola en un nuevo contexto, sino también resignificándola dentro de las particularidades de producción de los entornos locales.

\section{Referencias}

DRAE

2012 Diccionario de la Real Academia de la Lengua Española, documento electrónico disponible en [http://rae. es], consultado el 29 enero de 2012.

Barthes, Roland

1989 La cámera lúcida, Barcelona, Páidos.

González, Laura

2011 André Malraux, Las voces del silencio: visión del arte, documento electrónico disponible en [http://www. lauragonzalez.com/Malraux-Museo. pdf], consultado el 1 de diciembre de 2011.
Lugar a Dudas

2011 Calco de Richard Hamilton, documento electrónico disponible en [http://www.lugaradudas.org/archivo/2011/exhibiciones/261111_calco_ richard_hamilton.html], consultado el 20 de octubre de 2011.

Malraux, André

1951 "Le musée imaginaire", en Les voix du silence, París, Nouvelle Revue Française / Gallimard.

O'Doherty, Brian

1986 Inside the White Cube: The Ideology of the Gallery Space, San Francisco, Lapis Press.

Rummel, Stan

2006 "Just what is it that makes today's homes so different, so appealing?" por Richard Hamilton, documento electrónico disponible en [http://faculty.txwes.edu/csmeller/Human-Prospect/ProData09/03WW2CulMatrix/ WW2PICs/PopArt/Hamilton1922/Hamilton1956Just444.htm], consultado el 20 octubre de 2011. 